\title{
CHARACTERIZATION AND POTENTIAL SUITABILITY OF SIMAROUBA GLAUCA SEED SHELL LIGNOCELLULOSIC BIOMASS AS ADSORBENT OF BASIC DYES FROM AQUEOUS SOLUTIONS
}

\author{
JEYAGOWRI BALAKRISHNAN* and YAMUNA RANGAIYA THIAGARAJAN** \\ *Department of Chemistry, Hindusthan College of Engineering and Technology, Coimbatore, India \\ *** Department of Chemistry, KIT - Kalaignarkarunanidhi Institute of Technology, Coimbatore, India \\ Corresponding author: J. Balakrishnan, gowrivasu2007@gmail.com
}

Received October 5, 2020

\begin{abstract}
The present study investigates the potential of Simarouba glauca seed shell powder as a cost-effective adsorbent for the removal of the cationic dyes Malachite green (MG), Methylene blue (MB) and Rhodamine B (RB) from aqueous solutions. The adsorbent was characterized by Fourier transform infrared spectroscopy (FTIR), scanning electron microscopy (SEM) and X-ray diffraction (XRD), as well as by Brunauer-Emmett-Teller (BET) and elemental (CHNS) analyses. Batch mode adsorption studies were carried out varying the experimental conditions, such as initial dye concentration and contact time, adsorbent dose, $\mathrm{pH}$ and particle size, in order to assess the adsorbent capacity for the removal of cationic dyes from wastewater. The experimental data were analysed using the Langmuir, Freundlich, Temkin and Dubinin-Radushkevich isotherms. The data fitted well the Langmuir model for the dyes studied. Kinetic data were analysed using the pseudo-first order, pseudo-second order, intraparticle diffusion and Boyd models. The experimental results showed that the pseudo-second order model fitted well.
\end{abstract}

Keywords: biosorption, Simarouba glauca seed shell, cationic dyes, adsorption isotherm, kinetic studies

\section{INTRODUCTION}

Water is an essential resource for life. With the help of science and technology, mankind is reaching new horizons in many sectors, but the cost that is paid or will be paid in the near future for these achievements will be too high. ${ }^{1}$ Among the consequences of this rapid growth, environmental pollution has become a major and most urgent problem, with critical implications. ${ }^{2}$ Water pollution with toxic compounds is one of the major concerns for human health as well as for environmental quality. The main source of water pollution can be attributed to discharge of untreated sanitary and toxic industrial wastes, dumping of industrial effluents and runoff from agricultural fields. Nowadays, with the rapid development of modern industries, the contamination of water associated with dyes present in the effluents of various industries, such as dyeing, printing, textile, leather and coating industries, has drawn much attention. ${ }^{3}$ Though industries such as paper and pulp mills, dyestuff, distilleries and tanneries produce highly colored wastewater, it is the textile industry that contributes the most to water pollution with the discharge of large quantities of aqueous waste and dye effluents.

Dyeing wastewaters contain strong color, high amounts of suspended solids, broadly fluctuating $\mathrm{pH}$, high BOD and COD values. Dyes are usually of synthetic origin and have complex aromatic structure, which makes them highly stable and more difficult to biodegrade. ${ }^{4}$ The discharge of dye wastewater imparts color to receiving streams and affects their aesthetic value. Dyeing wastewaters interfere with the penetration of sunlight into water, retarding photosynthesis, inhibit the growth of aquatic biota and interfere with the solubility of gases in water bodies. ${ }^{5}$

Dyeing wastewater can be treated by numerous methods, such as adsorption, coagulation, advanced oxidation, membrane separation, aerobic and anaerobic microbial degradation. Among all these methods, adsorption emerged as a cost-effective and eco-friendly technology, with several advantages, such as low initial cost, simplicity in design, ease of operation 
and efficient removal of pollutants from wastewater. Activated carbon is commercially used as an adsorbent due to its capability to efficiently adsorb a broad range of adsorbates. ${ }^{6}$ Despite its wide use, the application of activated carbon is restricted due to its high cost. Thus, studies pertaining to alternative low-cost adsorbents have emerged in order to replace activated carbon in pollution control through the adsorption process.

Agricultural residues are a viable option as raw materials for the development of adsorbents for water treatment, as they are economic and eco-friendly, as well as due to their unique chemical composition, abundant availability, renewability and reduced disposal costs. Numerous agricultural wastes/by-products, such as raw Brazil nut shell, ${ }^{7}$ wood apple shell, ${ }^{8}$ walnut shell, ${ }^{9,10}$ maize cob, ${ }^{11,12}$ sugar beet pulp, ${ }^{13}$ coir pith, ${ }^{14}$ sawdust ${ }^{15,16}$ and sugarcane bagasse, ${ }^{17}$ have been investigated as adsorbents for the removal of dyes.

The present study explores the potential feasibility of Simarouba glauca seed shell powder for the removal of cationic dyes Malachite green, Methylene blue and Rhodamine B from aqueous solution. Simarouba glauca is commonly known as paradise tree or Laxmitaru, it belongs to the Simaroubaceae family native to North America, now found in different regions of India, such as Orissa, Karnataka and Gujarat. Simarouba glauca is an edible oil seed bearing tree, well suited for warm, humid and tropical regions. This tree, with its well-developed root system and evergreen dense canopy, efficiently prevents soil erosion and supports soil microbial life. The seed contains about $50-60 \%$ oil, with $63 \%$ unsaturated fatty acids, among which $59.1 \%$ is oleic acid, which is suitable for human consumption. The oil is also used in the manufacture of soaps, lubricants, paints and cosmetics. The oilseed cake, rich in nitrogen, serves as good organic manure. The efficient production of biodiesel from Simarouba glauca seed oil has been investigated by several researchers. ${ }^{18}$ The present study uses Simarouba glauca seed shell for the removal of basic dyes MG, MB and RB from aqueous solutions.

\section{EXPERIMENTAL}

\section{Materials}

Simarouba glauca seed shells were collected from Gujarat, India. Basic dyes, such as Malachite green (MG), Methylene blue (MB) and Rhodamine B (RB), were chosen for the present study. The dyes Malachite green and Methylene blue were purchased from SFCL Limited, New Delhi, and the dye Rhodamine B was purchased from SD Fine Chem Limited, Mumbai. Stock solutions of the dyes were prepared by dissolving $1.0 \mathrm{~g}$ of dye in $1000 \mathrm{~mL}$ of double distilled water to obtain the concentration of $1000 \mathrm{mg} / \mathrm{L}$. The stock solutions were diluted to known initial concentrations of the dyes using double distilled water.

\section{Preparation and characterization of raw Simarouba seed shell powder (RSS)}

Simarouba glauca seed shells were washed with water and dried in sunlight. The dried seed shells were ground to fine powder and stored in an air tight container. The seed shell powder was washed with distilled water several times until the wash water was clear, and then dried in a hot air oven at $60{ }^{\circ} \mathrm{C}$ for $24 \mathrm{~h}$. The dried seed shell powder was sieved to different particle sizes $(<75 \mu \mathrm{m}, 75-150 \mu \mathrm{m}$ and $>150 \mu \mathrm{m})$, and stored in an air tight plastic container for further studies.

Fourier transform infrared spectroscopy (Shimadzu, model IR Affinity-1) analysis of the adsorbent before and after adsorption was performed to determine the surface functional groups and their participation in the adsorption process. The nature and surface characteristics of the adsorbent were analysed by X-ray diffraction (XRD) analysis using an X'Pert PRO X-ray diffractometer (PANalytical B.V., Almelo, the Netherlands). The surface morphology of the adsorbent was investigated by a scanning electron microscope (SEM, JSM-6390, JOEL). The surface area, pore volume and pore size distribution of the adsorbent were determined by the $\mathrm{N}_{2}$ adsorptiondesorption isotherm at $77 \mathrm{~K}$ using a BET (Brunauer, Emmett and Teller) surface area analyzer (Micromeritics ASAP 2020). The elemental analysis of the adsorbents was carried out using an Elementar Vario EL III. The $\mathrm{pH}_{\mathrm{zpc}}$ of the adsorbent was also determined.

\section{Batch mode adsorption studies}

Batch adsorption experiments were carried by adding $0.1 \mathrm{~g}$ of adsorbent (RSS) into $250 \mathrm{~mL}$ Erlenmeyer flasks containing $50 \mathrm{~mL}$ of different initial dye concentrations. The flasks were agitated in a rotary shaker at $30 \pm 2{ }^{\circ} \mathrm{C}$ until equilibrium was attained. The adsorbent was separated by centrifugation and the concentration of the dyes in the supernatant was determined at $\lambda_{\max } 617,667$ and $547 \mathrm{~nm}$ for MG, MB and $\mathrm{RB}$, respectively, using a visible spectrophotometer (Shimadzu Visible Spectrophotometer UVmini-1240V).

The amount of dye adsorbed onto the adsorbent was calculated by the following equation:

$\mathrm{q}_{\mathrm{e}}=\left[\left(\mathrm{C}_{0}-\mathrm{C}_{\mathrm{e}}\right) \times \mathrm{V}\right] / \mathrm{M}$

where $\mathrm{q}_{\mathrm{e}}$ is the amount of dye adsorbed at equilibrium time $(\mathrm{mg} / \mathrm{g}), \mathrm{C}_{0}$ and $\mathrm{C}_{\mathrm{e}}$ are the initial and equilibrium 
dye concentrations (mg/L), respectively, in solution. V is the volume $(\mathrm{L})$ of solution and $\mathrm{M}$ is the mass of adsorbent $(\mathrm{g})$.

\section{RESULTS AND DISCUSSION}

\section{Characterization of the adsorbent}

The main components of the Simarouba seed shell powder are cellulose, hemicelluloses and lignin. The FT-IR spectrum of RSS (Fig. 1) shows a broad band around $3402 \mathrm{~cm}^{-1}$ due to the stretching vibration of hydrogen bonded $\mathrm{O}-\mathrm{H}$ group in cellulose. The peaks observed at 2926 $\mathrm{cm}^{-1}$ and $1328 \mathrm{~cm}^{-1}$ correspond to the $\mathrm{C}-\mathrm{H}$ stretching and bending vibration of methyl groups of cellulose and hemicelluloses, respectively. The absorption band at $1722 \mathrm{~cm}^{-1}$ is characteristic of the carbonyl group stretching in hemicelluloses. ${ }^{19}$ The absorption bands at $1616 \mathrm{~cm}^{-1}$ and $1516 \mathrm{~cm}^{-1}$ were due to aromatic $\mathrm{C}=\mathrm{C}$ stretching in the phenyl ring of the lignin structure. The absorption band at $1422 \mathrm{~cm}^{-1}$ may be attributed to the methoxy group of lignin in RSS. The strong band at $1034 \mathrm{~cm}^{-1}$ also confirms the lignin structure of RSS. The absorption band at $1234 \mathrm{~cm}^{-1}$ may be due to the $\mathrm{C}-\mathrm{O}$ stretching in phenols. ${ }^{20,21}$

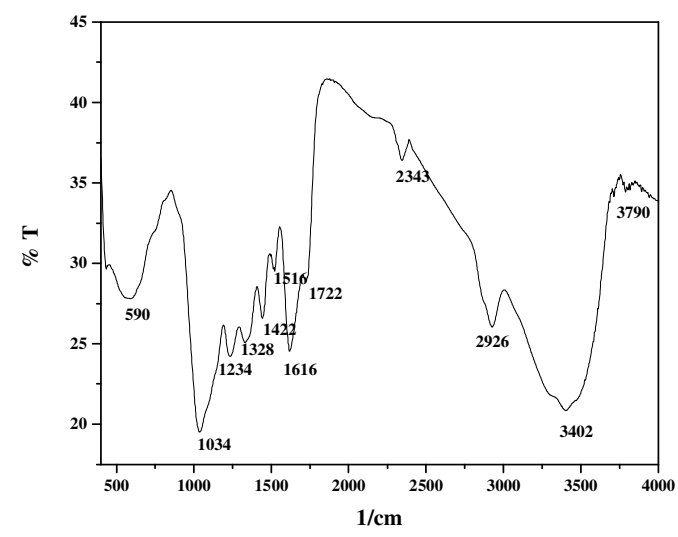

Figure 1: FT-IR spectrum of RSS
Table 1 clearly shows the FT-IR spectral analysis data before and after adsorption. The FTIR spectra of the dye loaded adsorbents (Fig. 2) show changes in intensity and slight shifting in the position of the peaks. The shift in the position of the peaks corresponding to the $\mathrm{C}-\mathrm{H}$ bending vibration of methyl groups of hemicelluloses, $\mathrm{C}=\mathrm{O}$ stretching in hemicelluloses, aromatic $\mathrm{C}=\mathrm{C}$ stretching in the phenyl ring of lignin and $\left(\mathrm{OCH}_{3}\right)$ group of lignin confirms the interaction of these functional groups of the adsorbent with the dye molecules.

Scanning electron microscopy was employed to observe the morphological features and surface characteristics of the adsorbents. SEM studies also revealed the surface texture and porosity of the adsorbent materials. Figure $3 \mathrm{a}$ shows an uneven, porous and rough surface for RSS, which facilitates the adsorption of dye molecules onto the adsorbent surface. The SEM images of the dye loaded adsorbents (Fig. 3b, 3c and 3d) reveal smooth surfaces, as the pore cavities were covered with the dye molecules.

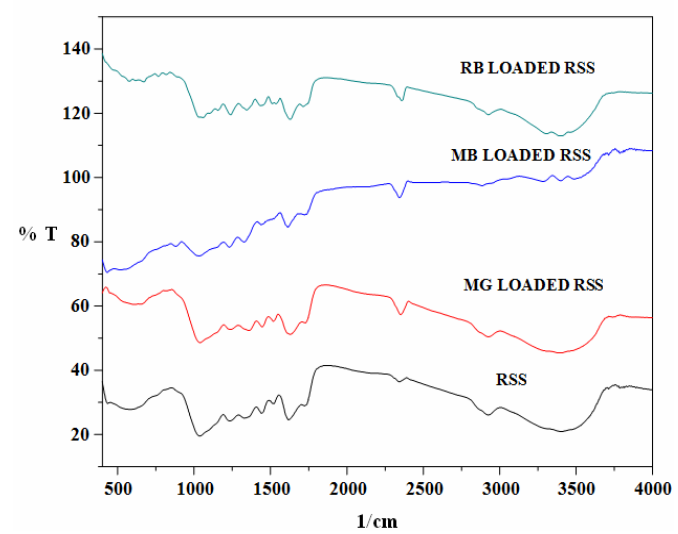

Figure 2: FT-IR spectra of dye loaded RSS

Table 1

FTIR characteristics of RSS

\begin{tabular}{|c|c|c|c|c|}
\hline \multirow{2}{*}{ Functional group } & \multicolumn{4}{|c|}{ Wavenumber $\left(\mathrm{cm}^{-1}\right)$} \\
\hline & RSS & MG-RSS & MB-RSS & RB-RSS \\
\hline$-(\mathrm{OH})$ stretching & 3402 & 3398 & 3400 & 3396 \\
\hline -(CH) stretching (cellulose) & 2926 & 2927 & 2885 & 2926 \\
\hline - $(\mathrm{CH})$ bending (hemicelluloses) & 1328 & 1359 & 1327 & 1346 \\
\hline$-(\mathrm{CO})$ stretching & 1722 & 1726 & - & 1714 \\
\hline$-\mathrm{C}=\mathrm{C}$ aromatic (lignin) & 1616 & 1629 & 1608 & 1629 \\
\hline$-\mathrm{C}=\mathrm{C}$ aromatic (lignin) & 1516 & 1517 & - & 1514 \\
\hline$-\left(\mathrm{OCH}_{3}\right)($ lignin $)$ & 1422 & 1446 & 1438 & 1435 \\
\hline$-(\mathrm{C}-\mathrm{O})$ stretching & 1234 & 1238 & 1230 & 1240 \\
\hline
\end{tabular}



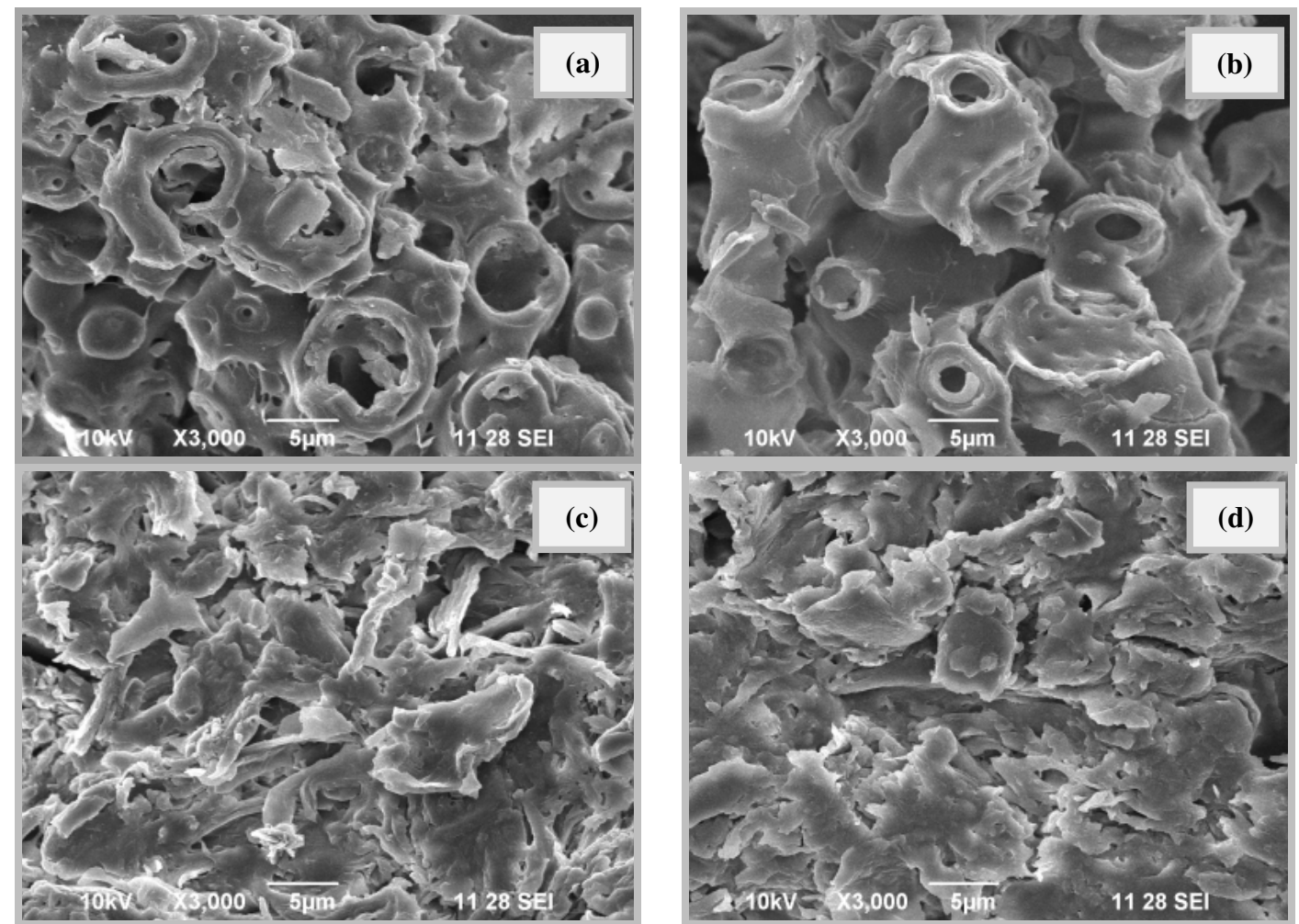

Figure 3: SEM images of a) RSS, b) RSS loaded with RB, c) RSS loaded with MG, d) RSS loaded with MB

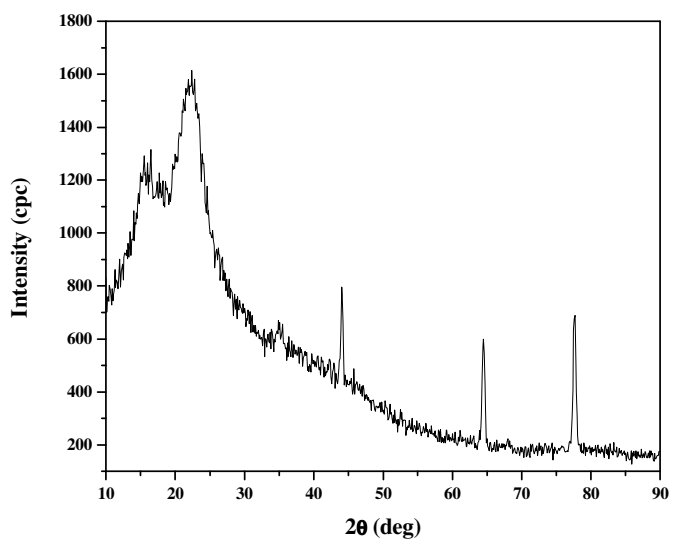

Figure 4: XRD pattern of RSS

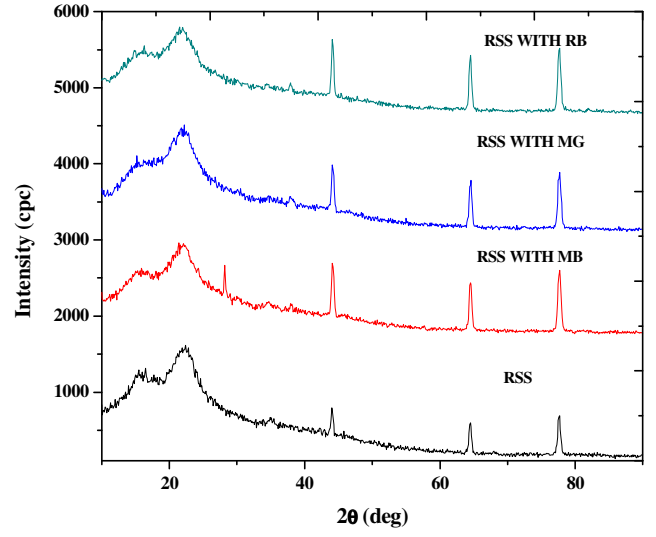

Figure 5: XRD pattern of dye loaded RSS

largest peak (at around $22^{0}$ ) indicates the presence of highly organized cellulose, whereas the smallest peak (at around $16^{0}$ ) indicates the presence of a less organized polysaccharide structure. $^{22}$

When the dye molecules get adsorbed onto the adsorbent, the crystalline nature of the adsorbent undergoes significant changes. Figure 5 shows the diffraction pattern of the dye loaded RSS. The XRD pattern of the dye loaded adsorbent shows 
an increase in intensity of the characteristic peaks, which indicates an improvement in the crystalline nature of the adsorbent, probably due to crystal growth as a result of the dye sorption reaction.

Figure 6 shows the pore size distribution of the adsorbent and Table 2 presents the BET surface area and average pore diameter. It is clear that most of the pores of the three prepared adsorbents were in the mesoporous range, which has been confirmed by the average pore diameter. The elemental analysis of RSS was also done and the composition is shown in Table 2.

\section{Effect of initial dye concentration and contact time}

The initial dye concentration provides an important driving force to overcome mass transfer resistances of all molecules between the aqueous and solid phases. ${ }^{23}$ The contact time between the adsorbate and the adsorbent is of great importance in wastewater treatment by adsorption. The contact time required to reach the equilibrium state depends on the initial dye concentration and the adsorption capacity increases with the initial dye concentration. A rapid uptake of dyes, with a short equilibrium time, decides the efficiency of the adsorbent for its use in wastewater treatment. The effects of initial dye concentration and contact time on the adsorption of MG, MB and $\mathrm{RB}$ dyes onto the adsorbent RSS are shown in Figure 7. The contact time curve for the adsorption of MG, MB and RB onto RSS is smooth and continuous, leading to saturation due to the intraparticle diffusion process. The removal of dyes by adsorption onto RSS is initially rapid, then it proceeds at a slower rate and finally attains saturation. At the saturation point, the amount of dye adsorbed reaches a state of dynamic equilibrium with the amount of dyes in the solution. ${ }^{17}$ The phenomenon of rapid dye uptake in the initial period of contact time can be explained by the fact that a large number of surface sites are available for adsorption, while after a period of time, the remaining surface sites are difficult to occupy because of the repulsive forces between the solute molecules in solid and bulk phases. ${ }^{24}$



Figure 6: Pore size distribution of RSS

Table 2

Physicochemical characterization of RSS

\begin{tabular}{lc}
\hline Parameters & Values \\
\hline BET surface area & $2.0307 \mathrm{~m}^{2} / \mathrm{g}$ \\
Total pore volume & $0.004100 \mathrm{~cm}^{3} / \mathrm{g}$ \\
Average pore diameter & $12.243 \mathrm{~nm}$ \\
Zero point charge $\left(\mathrm{pH}_{\text {zpc }}\right)$ & 3.4 \\
$\mathrm{C} \%$ & 51.40 \\
$\mathrm{H} \%$ & 6.036 \\
$\mathrm{~N} \%$ & 1.01 \\
$\mathrm{~S} \%$ & 0.12 \\
\hline
\end{tabular}



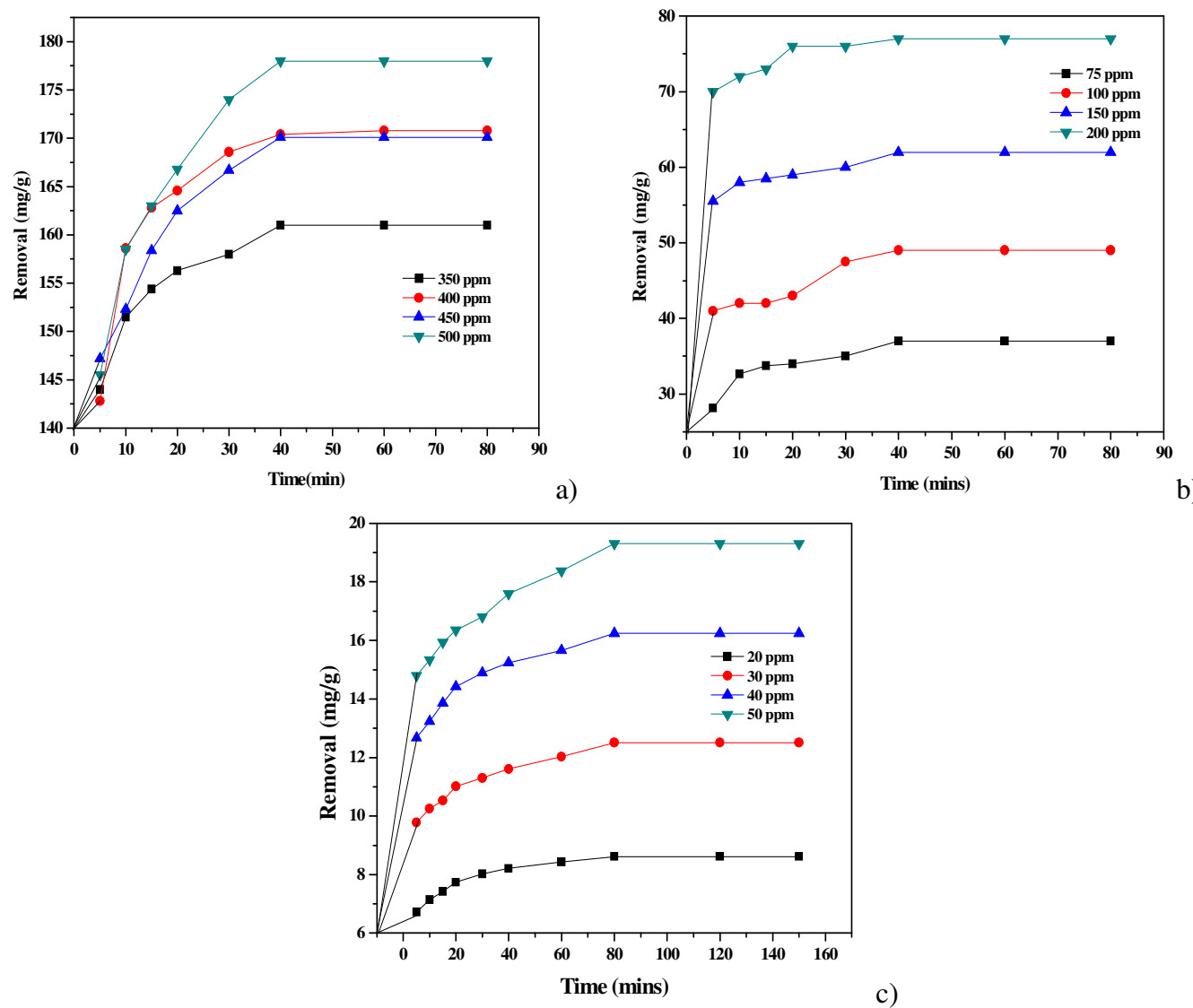

c)

Figure 7: Effect of contact time and initial dye concentration on adsorption of a) MG, b) MB, and c) $\mathrm{RB}$ onto RSS (adsorbent dose $=0.1 \mathrm{~g} / 50 \mathrm{~mL}$ )

\section{Effect of $p H$}

The influence of removal of dye molec

(b) slution $\mathrm{pH}$ on the 1 be explained based on the $\mathrm{pH}$ at the point zero charge $\left(\mathrm{pH}_{\mathrm{zpc}}\right)$ of the adsorbent. The $\mathrm{pH}_{\mathrm{zpc}}$ is a convenient index, showing the $\mathrm{pH}$ of the solution when the surface of the adsorbent has zero charge. When the $\mathrm{pH}$ of the solution is lower than $\mathrm{pH}_{\mathrm{zpc}}$, the surface of the adsorbent becomes positively charged, and when the $\mathrm{pH}$ of the solution is greater than $\mathrm{pH}_{\mathrm{zpc}}$, the surface becomes negatively charged. ${ }^{25}$ The $\mathrm{pH}_{\mathrm{zpc}}$ of RSS was found to be 3.4. The adsorption of MG, MB and RB by RSS was studied over the $\mathrm{pH}$ range of 2-11. From Figure 8, it can be observed that the adsorption capacity of RSS, in the case of $\mathrm{MG}$ and $\mathrm{MB}$ adsorption, increased, as the $\mathrm{pH}$ value rose from 2 to 8 , and remained constant with further increase in $\mathrm{pH}$ from 10 to 11 . This is probably due to the fact that at $\mathrm{pH}<\mathrm{pH}_{\mathrm{zpc}}$, the surface becomes positively charged, the concentration of $\mathrm{H}^{+}$ions is high and they compete with the dye cations for vacant adsorption sites, causing a decrease in dye uptake. At $\mathrm{pH}>\mathrm{pH}_{\mathrm{zpc}}$, the adsorbent surface becomes negatively charged and favours the uptake of cationic dyes due to an increased electrostatic force of attraction. The influence of $\mathrm{pH}$ in the case of $\mathrm{RB}$ removal by RSS shows the opposite trend, the increase in $\mathrm{pH}$ decreases the adsorption capacity of RSS. The amount of RB adsorbed increased from $\mathrm{pH} 2$ to 4, while further increase in $\mathrm{pH}$ from 4 to 11 decreased the adsorption of RB. The higher uptake of $\mathrm{RB}$ at lower $\mathrm{pH}$ may be probably explained by the fact that excess $\mathrm{H}^{+}$ions yielded the zwitterionic molecular form of the dye, enabling the dye molecules to attach to the negative sites of the adsorbent. The decrease in adsorption at $\mathrm{pH}>4$ may be due to the aggregation of the zwitterionic molecular form of RB, generating dimmers, which are unable to enter the pores of the adsorbent. ${ }^{26}$ a similar effect has been observed for adsorption using waste coir pith, ${ }^{27}$ sago waste carbon, ${ }^{28}$ activated carbon from bagasse pith ${ }^{29}$ and Turbinaria conoides. ${ }^{30}$ 
Lignocellulose
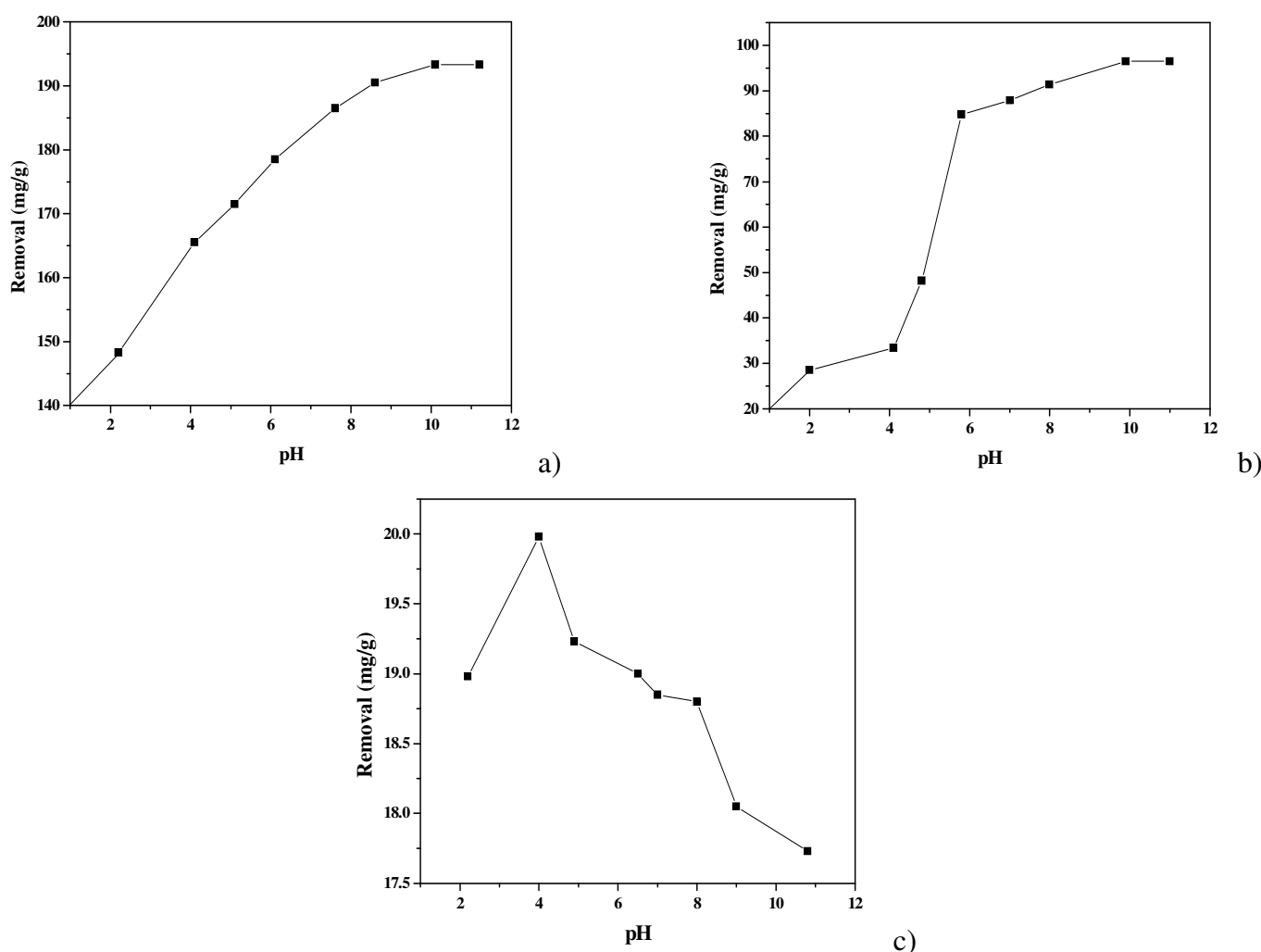

c)

Figure 8: Effect of $\mathrm{pH}$ on adsorption of a) MG, b) MB, and c) RB onto RSS

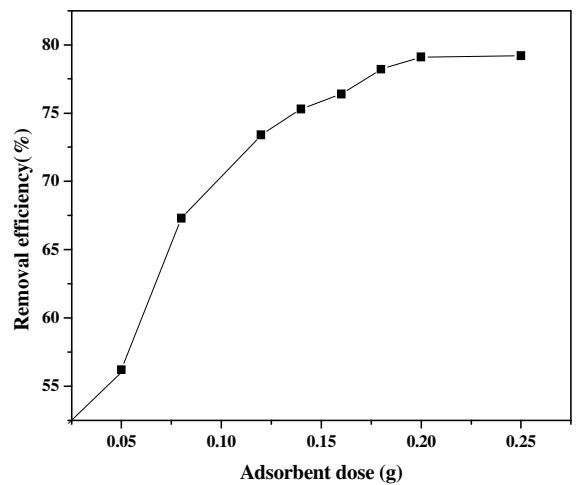

a)
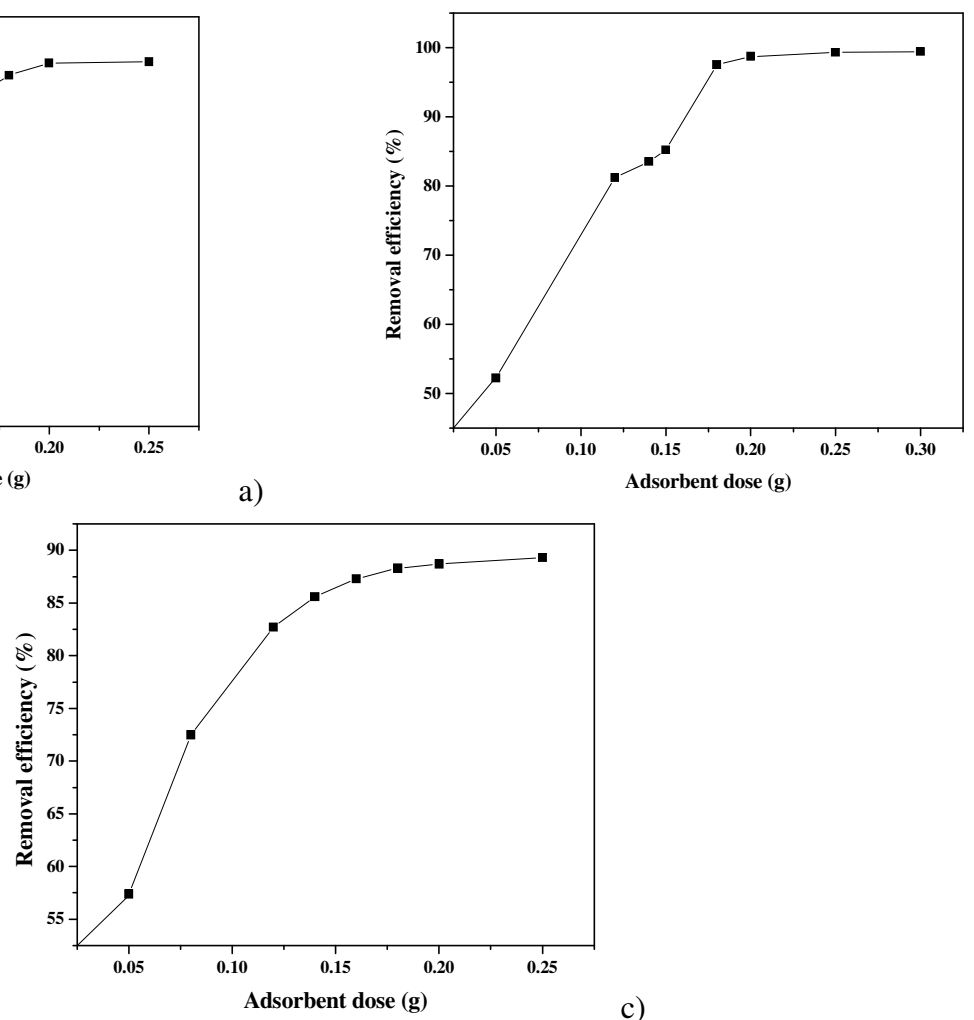

b)

c)

Figure 9: Effect of adsorbent dose on adsorption of a) MG, b) MB, and c) RB onto RSS 


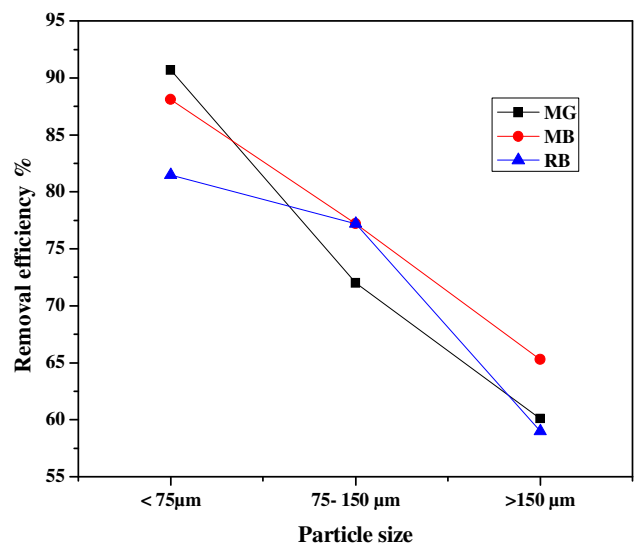

Figure 10: Effect of particle size on MG, MB and RB removal by RSS

\section{Effect of adsorbent dose}

The adsorbent dosage represents an important parameter due to its strong effect on the adsorption capacity of an adsorbent at a given initial concentration of an adsorbate. ${ }^{31}$ The effect of the RSS adsorbent dose on the removal of the dyes studied is presented in Figure 9. It can be observed that the dye removal increases with an increment in adsorbent dosage. The increase in the percentage of dye removal with the increase in adsorbent dose might be attributed to an increase in the surface area of the adsorbent and in the number of adsorption sites available for adsorption.

\section{Effect of particle size}

The contact surface between the adsorbent and the adsorbate plays a major role in the process of adsorption. The adsorption rate of the dyes MG, $\mathrm{MB}$ and $\mathrm{RB}$ was examined for three different particle sizes of RSS $(<75 \mu \mathrm{m}, 75-150 \mu \mathrm{m}$ and $>150 \mu \mathrm{m}$ ), while keeping the other parameters concerning the dyes mnctant. The variation of the adsorption capacity (c) various particle sizes is shown in Figure 10.

The adsorption rate increased with a decrease in particle size. This is attributed to the availability of a larger surface area, which means greater accessibility of a higher number of active sites present in the adsorbent. The breaking up of large particles into smaller ones opens some tiny sealed channels, which might then become available for adsorption, leading to increased adsorption in smaller particles, compared to larger ones. ${ }^{32}$ In the case of larger particles, the diffusion resistance to mass transport is higher and most of the internal surface of the particles may not be utilized for adsorption. ${ }^{23}$

\section{Isotherm studies}

Langmuir adsorption isotherm

The Langmuir adsorption isotherm has been successfully applied to many adsorption processes and assumes monolayer adsorption onto a surface containing a finite number of adsorption sites, using uniform strategies of adsorption, with no transmigration of the adsorbate in the plane of the surface. ${ }^{33,34}$ The Langmuir isotherm is represented by the following equation: ${ }^{35}$

$\mathrm{C}_{\mathrm{e}} / \mathrm{q}_{\mathrm{e}}=1 / \mathrm{Q}_{0} \mathrm{~b}+\mathrm{C}_{\mathrm{e}} / \mathrm{Q}_{0}$

where $\mathrm{C}_{\mathrm{e}}(\mathrm{mg} / \mathrm{L})$ is the equilibrium concentration of the dye, $\mathrm{q}_{\mathrm{e}}(\mathrm{mg} / \mathrm{g})$ is the amount of dye adsorbed at equilibrium time and $\mathrm{Q}_{0}$ and $\mathrm{b}$ are Langmuir constants related to adsorption capacity and energy of adsorption, respectively. The Langmuir constants $\mathrm{Q}_{0}$ and $\mathrm{b}$ can be calculated from the slope and intercept of the linear plot of $\mathrm{C}_{\mathrm{e}} / \mathrm{q}_{\mathrm{e}}$ versus $\mathrm{C}_{\mathrm{e}}$. The Langmuir adsorption isotherms for the adsorption of the dyes MG, MB and RB onto RSS are shown in Figure 11 and the isotherm parameters are given in Table 3.

The Langmuir adsorption capacity, $\mathrm{Q}_{0}$, of the dyes $\mathrm{MG}, \mathrm{MB}$ and $\mathrm{RB}$ for the adsorption onto RSS was found to be 200, 76.92 and $33.33 \mathrm{mg} / \mathrm{g}$, respectively. The essential characteristics of the Langmuir adsorption isotherm can be expressed in terms of a dimensionless constant separation factor or equilibrium parameter $R_{L}$ defined by:

$\mathrm{R}_{\mathrm{L}}=1 /\left(1+\mathrm{K}_{\mathrm{L}} \mathrm{C}_{0}\right)$

where $\mathrm{C}_{0}$ is initial dye concentration $(\mathrm{mg} / \mathrm{L})$ and $\mathrm{K}_{\mathrm{L}}$ is the Langmuir constant $(\mathrm{L} / \mathrm{mg})$. $\mathrm{R}_{\mathrm{L}}$ values indicate whether the adsorption is unfavorable $\left(\mathrm{R}_{\mathrm{L}}\right.$ $=>1)$, linear $\left(\mathrm{R}_{\mathrm{L}}=1\right)$, favorable $\left(0<\mathrm{R}_{\mathrm{L}}<1\right)$, or irreversible $\left(R_{L}=0\right) .{ }^{35}$ The $R_{L}$ values presented in Table 3 clearly show the favorable adsorption of all three dyes onto RSS. A comparison of the 
adsorption capacities $\left(\mathrm{Q}_{0}\right)$ of various adsorbents

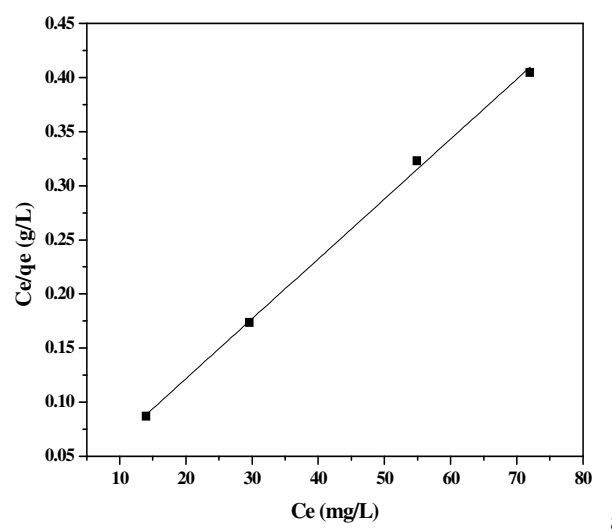

reported in the literature is presented in Table 4.



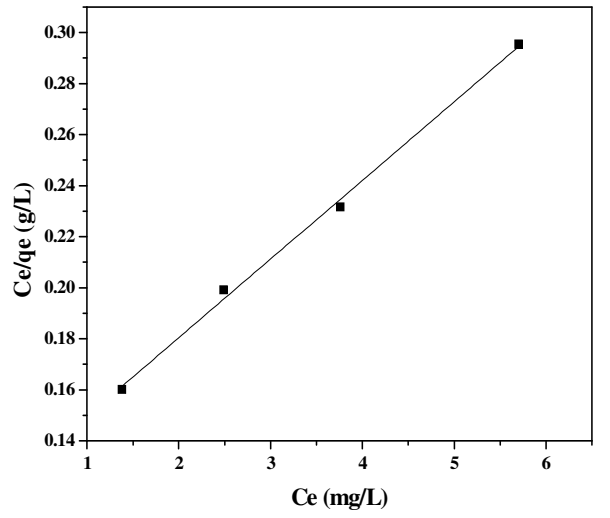

c)

Figure 11: Langmuir adsorption isotherm for the adsorption of a) MG, b) MB, and c) RB onto RSS

\section{Freundlich adsorption isotherm}

The Freundlich isotherm model is the earliest known equation describing the adsorption process. It is an empirical equation that can be used for non-ideal sorption, which involves heterogeneous adsorption. The Freundlich isotherm can be derived assuming a logarithmic decrease in the enthalpy of adsorption with the increase in the fraction of occupied sites and is commonly given by the following non-linear equation: ${ }^{32}$

$\mathrm{q}_{\mathrm{e}}=\mathrm{K}_{\mathrm{f}} \mathrm{C}_{\mathrm{e}} 1 / \mathrm{n}$

where $\mathrm{K}_{\mathrm{f}}$ and $\mathrm{n}$ are Freundlich constants, where $\mathrm{K}_{\mathrm{f}}(\mathrm{L} / \mathrm{g})$ is the adsorption capacity of an adsorbent and shows the strength between the adsorbate and the adsorbent, while the value of $n(g / L)$ indicates the favorability of the adsorption process.

The value of $1 / n$ indicates the adsorption intensity of the dye onto the adsorbent and values closer to zero denote surface heterogeneity. A value of $1 / n$ below 1 indicates favorable adsorption, while $1 / n$ above 1 is indicative of cooperative adsorption. ${ }^{33}$ The linear form of the equation is expressed as:

$\ln \mathrm{q}_{\mathrm{e}}=\ln \mathrm{K}_{\mathrm{f}}+1 / \mathrm{n} \ln \mathrm{C}_{\mathrm{e}}$

The values of $K_{f}$ and $n$ were calculated from the intercept and the slope of the linear plot of $\ln \mathrm{q}_{\mathrm{e}}$ vs $\ln C_{\mathrm{e}}$, and are given in Table 3 .

The value of $\mathrm{K}_{\mathrm{f}}$ indicates the affinity of the dyes towards the adsorbent, the greater the value of $\mathrm{K}_{\mathrm{f}}$, the greater is the affinity of the dyes. In the present work, MG has the highest $\mathrm{K}_{\mathrm{f}}$ value, of $140.75(\mathrm{~L} / \mathrm{g})$, compared to the other dyes, which shows that MG has a higher affinity to the adsorbent. The values of $1 / \mathrm{n}$ for all the dyes studied were below one, which indicates favorable adsorption.

\section{Temkin isotherm}

The Temkin isotherm equation contains a factor that explicitly takes into account adsorbing species-adsorbate interactions. It assumes that the heat of adsorption of all the molecules in the layer 
would decrease linearly with coverage due to adsorbate-adsorbate repulsions and the adsorption is a uniform distribution of maximum binding energy. ${ }^{36}$ The non-linear form of the Temkin isotherm is commonly represented as: ${ }^{37}$

$\mathrm{q}_{\mathrm{e}}=\mathrm{RT} / \mathrm{b} \ln \left(\mathrm{K}_{\mathrm{t}} \mathrm{C}_{\mathrm{e}}\right)$

The linear form of Temkin isotherm is expressed as:
$\mathrm{q}_{\mathrm{e}}=\mathrm{B}_{1} \ln \mathrm{K}_{\mathrm{t}}+\mathrm{B}_{1} \ln \mathrm{C}_{\mathrm{e}}$

where $\mathrm{B}_{1}=\mathrm{RT} / \mathrm{b}, \mathrm{Kt}$ is the equilibrium binding constant $(\mathrm{L} / \mathrm{mol})$ corresponding to the maximum binding energy and $\mathrm{B}_{1}$ is related to the heat of adsorption. The above constants are determined using the plot of $\mathrm{q}_{\mathrm{e}}$ vs $\ln \mathrm{C}_{\mathrm{e}}$. The values of constants $\mathrm{K}_{\mathrm{t}}$ and $\mathrm{b}$ are given in Table 3 .

Table 3

Isotherm parameters for adsorption of $\mathrm{MG}, \mathrm{MB}$ and $\mathrm{RB}$ onto RSS

\begin{tabular}{lcccc}
\hline Isotherm/Dye & & Malachite green & Methylene blue & Rhodamine B \\
\hline \multirow{4}{*}{ Langmuir } & $\mathrm{Q}_{0}(\mathrm{mg} / \mathrm{g})$ & 200.0 & 76.92 & 33.33 \\
& $\mathrm{~b}\left({\left.\mathrm{~L} / \mathrm{mg}^{-1}\right)}^{2}\right.$ & 0.500 & 1.083 & 0.250 \\
& $\mathrm{R}^{2}$ & 0.998 & 0.979 & 0.997 \\
& $\mathrm{R}_{\mathrm{L}}$ & 0.0039 & 0.0046 & 0.074 \\
\hline \multirow{3}{*}{ Freundlich } & $\mathrm{K}_{\mathrm{F}}(\mathrm{L} / \mathrm{g})$ & 140.75 & 45.20 & 7.286 \\
& $\mathrm{n}$ & 19.23 & 6.580 & 1.733 \\
& $\mathrm{R}^{2}$ & 0.854 & 0.931 & 0.992 \\
\hline \multirow{3}{*}{ Temkin } & $\mathrm{K}_{\mathrm{T}}(\mathrm{L} / \mathrm{g})$ & 8.816 & 8.283 & 7.628 \\
& $\mathrm{~b}(\mathrm{~kJ} / \mathrm{mol})$ & 302.1 & 267.7 & 2.185 \\
& $\mathrm{R}^{2}$ & 0.851 & 0.916 & 0.996 \\
\hline \multirow{3}{*}{$\mathrm{D}-\mathrm{R}$} & $\mathrm{Q}_{\mathrm{m}}(\mathrm{mol} / \mathrm{g})$ & 273.14 & 66.02 & 13.37 \\
& $\mathrm{E}(\mathrm{kJ} / \mathrm{mol})$ & 0.408 & 2.886 & 1.000 \\
& $\mathrm{R}^{2}$ & 0.810 & 0.846 & 0.948 \\
\hline
\end{tabular}

Table 4

Comparison of maximum adsorption capacities of various low-cost adsorbents for MG, MB and RB

\begin{tabular}{lccc}
\hline Adsorbent & Dye & $\mathrm{Q}_{0}(\mathrm{mg} / \mathrm{g})$ & References \\
\hline RSS & MG & 200.0 & This study \\
RSS & MB & 76.92 & This study \\
RSS & RB & 33.33 & This study \\
Lotus leaf & MG & 113.8 & 41 \\
Wood apple shell & MG & 34.56 & 48 \\
Walnut shell & MG & 90.8 & 10 \\
Ashoka leaf powder & MG & 83.3 & 43 \\
Green pea peels & MB & 163.94 & 36 \\
Rice husk & MB & 8.07 & 44 \\
Silkworm exuviae & MB & 25.53 & 25 \\
Modified wheat straw & MB & 257.8 & 50 \\
Sago waste & RB & 16.1 & 28 \\
Turbinaria conoides & RB & 80 & 30 \\
Jute stick powder & RB & 87.7 & 46 \\
Ashoka leaf powder & RB & 66.6 & 43 \\
\hline
\end{tabular}

\section{Dubinin-Radushkevich (D-R) isotherm}

The D-R isotherm is more general because it does not assume a homogenous surface or constant adsorption potential and is applied to estimate the porosity, apparent free energy and the characteristics of adsorption. The linear form of the D-R isotherm is represented as: ${ }^{38}$

$\ln \mathrm{Q}_{\mathrm{e}}=\ln \mathrm{Q}_{\mathrm{m}}-\beta \varepsilon^{2}$ where $Q_{m}$ is the maximum adsorption capacity $\left(\mathrm{mg} \mathrm{g}^{-1}\right), \beta$ is the D-R isotherm constant and $\varepsilon$ is the Polanyi potential. The constants $\beta\left(\mathrm{mol}^{2} \mathrm{KJ}^{-2}\right)$ and $\mathrm{Q}_{\mathrm{m}}\left(\mathrm{mg} \mathrm{g}^{-1}\right)$ can be calculated from the slope and intercept of the plot $\ln \mathrm{q}_{\mathrm{e}} \mathrm{vs} \varepsilon^{2}$ and are presented in Table 3. The Polanyi potential, $\varepsilon$, represents the work required to remove a molecule from its location and can be calculated as follows: 
$\varepsilon=\mathrm{RT} \ln \left(1+1 / \mathrm{C}_{\mathrm{e}}\right)$

The mean free energy of adsorption $(\mathrm{E})$ is the free energy when one mole of ions is transferred from infinity in solution to the surface of the sorbent. $\mathrm{E}$ is calculated as follows:

$\mathrm{E}=(-2 \beta)^{1 / 2}$

The value of $\mathrm{E}$ would provide information about the nature of adsorption - whether it is physisorption or chemisorption. The adsorption process is physisorption when $\mathrm{E}$ lies between 1 and $8 \mathrm{KJ} \mathrm{mol}^{-1}$, while it is chemisorption when $\mathrm{E}$ is higher than $8 \mathrm{KJ} \mathrm{mol}^{-1}$. The $\mathrm{D}-\mathrm{R}$ isotherm parameters are presented in Table 3. From Table 3 , it is clear that the values of $\mathrm{E}$ lie in the range from 0.408 to $2.886 \mathrm{KJ} \mathrm{mol}^{-1}$, confirming that a weak physical force of interaction is the driving force of the adsorption of dyes onto RSS.

The isotherm parameters summarized in Table 3 reveal that the Langmuir adsorption isotherm model has a higher correlation coefficient $\mathrm{R}^{2}$ than the other models studied. The best fit of the Langmuir isotherm clearly indicates the monolayer coverage of the dye molecules onto the outer surface of the adsorbent.

\section{Adsorption kinetics}

The rate at which adsorption takes place is of utmost importance when designing batch adsorption systems, consequently, it is important to establish the time dependence of such systems under process conditions. ${ }^{39}$ The adsorption kinetics were analyzed using pseudo-first order, pseudo-second order, Weber-Morris intraparticle diffusion and Boyd models. The conformity between the experimental data and the model predicted values was expressed by the correlation coefficient $\left(\mathrm{R}^{2}\right)$ values. A relatively high $\mathrm{R}^{2}$ value indicates that the model successfully describes the kinetics of adsorption.

\section{Pseudo-first order model}

The pseudo-first order model is the earliest known model suggested for the sorption of liquid/solid systems based on solid capacity. The Lagergren rate equation is the most widely used adsorption rate equation for adsorption from aqueous solutions. The Lagergren pseudo-first order model can be represented as:

$$
\frac{d q_{t}}{d t}=k_{1}\left(q_{e}-q_{t}\right)
$$

A linear form of the pseudo-first order model is represented as follows: ${ }^{40}$

$\log \left(\mathrm{q}_{\mathrm{e}}-\mathrm{q}_{\mathrm{t}}\right)=\log \mathrm{q}_{\mathrm{e}}-\left(\mathrm{K}_{1} \mathrm{t}\right) / 2.303$

where $\mathrm{q}_{\mathrm{e}}$ and $\mathrm{q}_{\mathrm{t}}$ are the amount of dye adsorbed at equilibrium and at time $\mathrm{t}(\mathrm{mg} / \mathrm{g})$, respectively, and $\mathrm{K}_{1}\left(\mathrm{~min}^{-1}\right)$ is the rate constant of adsorption. The values of $\mathrm{K}_{1}$ and $\mathrm{q}_{\mathrm{e}}{ }^{\mathrm{cal}}$ were calculated from the slope and intercept of the plot of $\log \left(q_{e}-q_{t}\right)$ vs $t$, respectively. The values of the pseudo-first order rate constant $\mathrm{K}_{1}$ and $\mathrm{q}_{\mathrm{e}}^{\mathrm{cal}}$ were determined and the correlation coefficients $\mathrm{R}^{2}$ were presented in Table 5. A comparison of $\mathrm{q}_{\mathrm{e}}^{\mathrm{cal}}$ and $\mathrm{q}_{\mathrm{e}}{ }^{\mathrm{exp}}$ values, and the correlation coefficients $\mathrm{R}^{2}$ presented in Table 5 indicate the poor fit of the pseudo-first order model for all the dyes studied.

\section{Pseudo-second order model}

The adsorption may also be described by the pseudo-second order kinetic model, if the adsorption does not follow the first order kinetics.

The second order kinetic model is represented as: $:^{41}$

$\frac{d q_{t}}{d t}=k_{2}\left(q_{e}-q_{t}\right)^{2}$

The linear form of the pseudo-second order model is represented as:

$\mathrm{t} / \mathrm{q}_{\mathrm{t}}=1 / \mathrm{K}_{2} \mathrm{q}_{\mathrm{e}}^{2}+\mathrm{t} / \mathrm{q}_{\mathrm{e}}$

where $K_{2}$ is the rate constant of adsorption $(\mathrm{g} / \mathrm{mg}$ $\min ), \mathrm{q}_{\mathrm{e}}$ and $\mathrm{q}_{\mathrm{t}}$ are the amount of dye adsorbed $(\mathrm{mg} / \mathrm{g})$ at equilibrium and time $\mathrm{t}(\mathrm{min})$. The values of $\mathrm{K}_{2}$ and $\mathrm{q}_{\mathrm{e}}{ }^{\mathrm{cal}}$ were calculated from the intercept $\left(1 / \mathrm{K}_{2} \mathrm{q}_{\mathrm{e}}{ }^{2}\right)$ and slope $\left(1 / \mathrm{q}_{\mathrm{e}}\right)$ of the plot $\mathrm{t} / \mathrm{q}_{\mathrm{t}} \mathrm{vs} \mathrm{t}$, respectively. The pseudo-second order plots for the adsorption of $\mathrm{MG}, \mathrm{MB}$ and $\mathrm{RB}$ onto RSS are presented in Figure 12.

The pseudo-second order parameters, such as rate constant $\mathrm{K}_{2}, \mathrm{q}_{\mathrm{e}}$ cal and correlation coefficient $\mathrm{R}^{2}$, are presented in Table 5. It was observed that the correlation coefficient $\mathrm{R}^{2}$ values for the pseudosecond order model were higher that the $\mathrm{R}^{2}$ values for the pseudo-first order model. The $\mathrm{q}_{\mathrm{e}}{ }^{\mathrm{cal}}$ values of all the dyes were found to be in good agreement with the $\mathrm{q}_{\mathrm{e}}{ }^{\mathrm{exp}}$ values of the adsorbents. The good agreement of $\mathrm{q}_{\mathrm{e}}{ }^{\mathrm{cal}}$ values with $\mathrm{q}_{\mathrm{e}}{ }^{\text {exp }}$ values and the high $\mathrm{R}^{2}$ values of the pseudosecond order model confirm that the adsorption of the MG, MB and RB dyes onto RSS follows the pseudo-second order mechanism. 


\section{JEYAGOWRI BALAKRISHNAN and YAMUNA RANGAIYA THIAGARAJAN}

Table 5

Kinetic parameters for the adsorption of MG, MB and RB onto RSS at different initial concentrations

\begin{tabular}{|c|c|c|c|c|c|c|c|c|c|c|}
\hline \multirow[b]{2}{*}{ Dyes } & \multirow{2}{*}{$\begin{array}{l}\text { Conc. } \\
(\mathrm{mg} / \mathrm{L})\end{array}$} & \multirow{2}{*}{$\begin{array}{c}\mathrm{q}_{\mathrm{e}}^{\exp } \\
(\mathrm{mg} / \mathrm{g})\end{array}$} & \multicolumn{3}{|c|}{ Pseudo-first order } & \multicolumn{3}{|c|}{ Pseudo-second order } & \multicolumn{2}{|c|}{ Intraparticle diffusion } \\
\hline & & & $\begin{array}{c}\mathrm{q}_{\mathrm{e}}^{\mathrm{cal}} \\
(\mathrm{mg} / \mathrm{g})\end{array}$ & $\begin{array}{c}\mathrm{K}_{1} \\
\left(\min ^{-1}\right)\end{array}$ & $\mathrm{R}^{2}$ & $\begin{array}{c}\mathrm{q}_{\mathrm{e}}^{\mathrm{cal}} \\
(\mathrm{mg} / \mathrm{g})\end{array}$ & $\begin{array}{c}\mathrm{K}_{2} \\
\text { (g/mg min) }\end{array}$ & $\mathrm{R}^{2}$ & 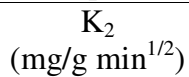 & $\mathrm{R}^{2}$ \\
\hline \multirow{4}{*}{ MG } & 350 & 161.0 & 20.13 & 0.066 & 0.960 & 166.6 & 0.009 & 1 & 2.278 & 0.781 \\
\hline & 400 & 170.4 & 39.72 & 0.101 & 0.978 & 200.0 & 0.005 & 1 & 3.415 & 0.681 \\
\hline & 450 & 170.1 & 36.39 & 0.075 & 0.994 & 200.0 & 0.004 & 0.999 & 3.492 & 0.828 \\
\hline & 500 & 178.0 & 48.31 & 0.078 & 0.983 & 200.0 & 0.003 & 0.999 & 4.579 & 0.810 \\
\hline \multirow{4}{*}{ MB } & 75 & 37.12 & 9.440 & 0.055 & 0.907 & 37.03 & 0.018 & 0.999 & 1.910 & 0.887 \\
\hline & 100 & 49.00 & 13.84 & 0.062 & 0.786 & 52.63 & 0.008 & 0.995 & 2.038 & 0.886 \\
\hline & 150 & 61.50 & 6.970 & 0.053 & 0.971 & 62.50 & 0.019 & 0.999 & 1.341 & 0.963 \\
\hline & 200 & 77.20 & 11.61 & 0.083 & 0.942 & 83.33 & 0.014 & 0.999 & 1.736 & 0.972 \\
\hline \multirow{4}{*}{$\mathrm{RB}$} & 20 & 8.260 & 2.198 & 0.034 & 0.995 & 8.849 & 0.047 & 0.999 & 0.183 & 0.830 \\
\hline & 30 & 12.51 & 3.069 & 0.030 & 0.994 & 12.82 & 0.026 & 0.999 & 0.282 & 0.899 \\
\hline & 40 & 16.24 & 3.908 & 0.032 & 0.986 & 16.66 & 0.022 & 0.999 & 0.359 & 0.870 \\
\hline & 50 & 19.30 & 5.296 & 0.028 & 0.992 & 20.00 & 0.013 & 0.999 & 0.489 & 0.924 \\
\hline
\end{tabular}



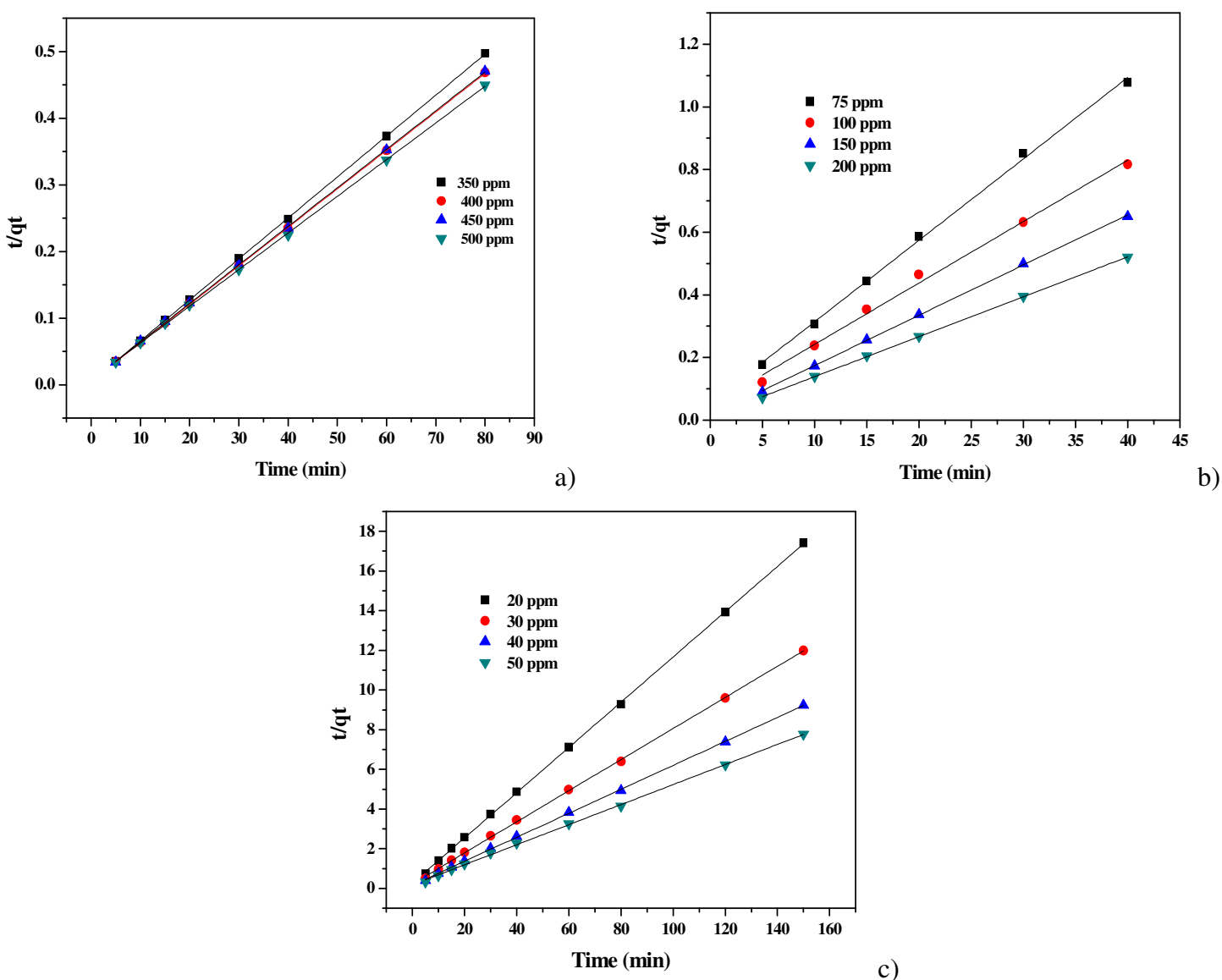

c)

Figure 12: Pseudo-second order plots for the adsorption of a) MG, b) MB, and c) RB onto RSS
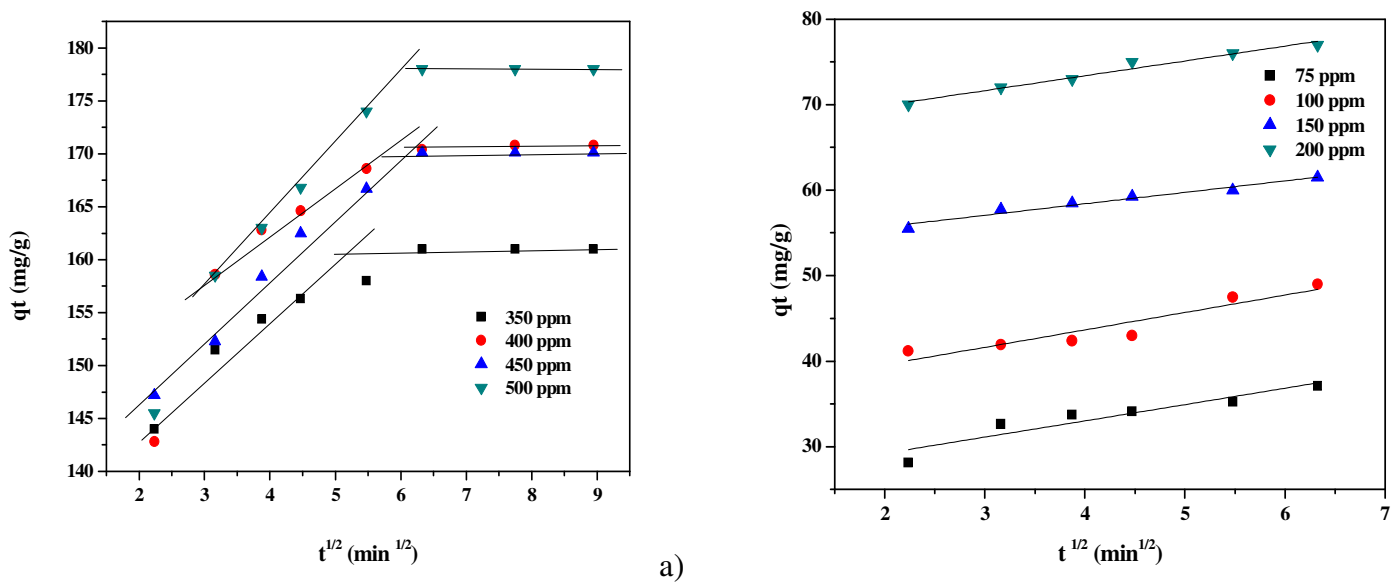

a)

b) 


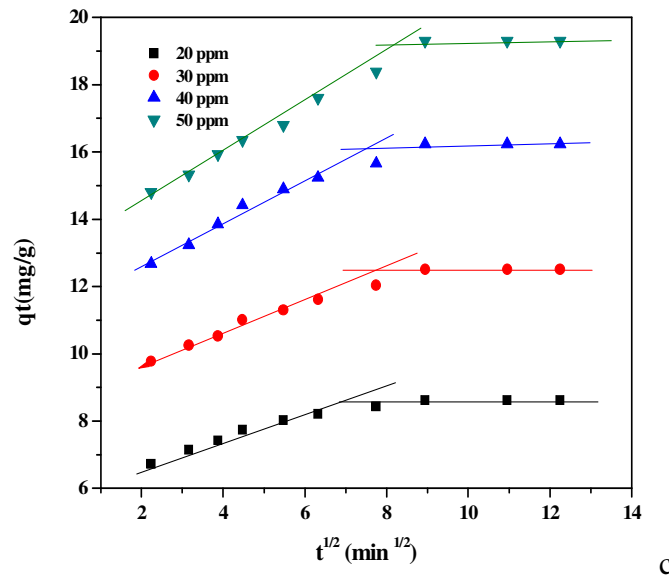

Figure 13: Intraparticle diffusion plots for the adsorption of a) MG, b) MB, and c) RB onto RSS

\section{Intraparticle diffusion studies}

In a solid liquid adsorption process, the transfer of solute from the liquid phase is usually characterized by either external mass transfer (boundary layer diffusion) or intraparticle diffusion or both. In order to investigate the diffusion mechanism and the rate controlling steps affecting the kinetics of adsorption, the kinetic data were fitted to Weber's intraparticle diffusion model.

Weber and Morris proposed an empirical relationship according to which, if intraparticle diffusion is the rate-controlling factor, the uptake of dyes varies with the square root of time. ${ }^{23}$ The intraparticle diffusion model is expressed as:

$\mathrm{q}_{\mathrm{t}}=\mathrm{K}_{\mathrm{id}} \mathrm{t}^{1 / 2}+\mathrm{C}_{\mathrm{i}}$

where $K_{i d}$ is the intraparticle diffusion constant $\left(\mathrm{mg} / \mathrm{gmin}^{1 / 2}\right)$ and $\mathrm{C}_{\mathrm{i}}$ is the intercept $(\mathrm{mg} / \mathrm{g})$. According to the intraparticle diffusion model equation, a plot of $\mathrm{q}_{\mathrm{t}} \mathrm{vs} \mathrm{t}^{1 / 2}$ should be a straight line with a slope $K_{i d}$ and intercept $C_{i}$, when the adsorption mechanism follows the intraparticle diffusion process. For the intraparticle diffusion model, it is essential that the plots of $q_{t} v s t^{1 / 2}$ should go through the origin, if the intraparticle diffusion is the sole rate-limiting step. ${ }^{23}$ Boundary layer thickness is represented by $\mathrm{C}_{\mathrm{i}}$. Higher values of $\mathrm{C}_{\mathrm{i}}$ correspond to a greater boundary layer.

The intraparticle diffusion plots $\left(\mathrm{q}_{\mathrm{t}}\right.$ versus $\left.\mathrm{t}^{1 / 2}\right)$ of MG, MB and RB adsorption onto RSS are shown in Figure 13 and intrapaticle diffusion parameters are presented in Table 5. The linearity of the plots clearly indicates that intraparticle diffusion plays a significant role in the uptake of dyes MG, MB and RB by RSS. In the present study, none of the plots passed through the origin, indicating that, though intraparticle diffusion is involved in the adsorption process, it was not the sole rate-limiting step. The adsorption of MB on RSS was linear over the whole time (Fig. 13), which is attributed to macropore diffusion, involving the instantaneous utilization of the most readily available adsorbing sites on the adsorbent surface. ${ }^{37}$ The non-zero intercept of the plots also reveals the co-existence of external film and intraparticle diffusions during the adsorption process. ${ }^{42}$

The linear plots of $q$ t versus $t^{1 / 2}$ for the adsorption of dyes MG and RB onto RSS show that the adsorption involves a two-step process. The first step involves the adsorption of dyes on the external surface of the adsorbent (film diffusion), whereas the second step represents the diffusion of dyes to the interior of the adsorption sites (intraparticle diffusion). ${ }^{23,43}$ Similar observations have been made regarding the adsorption of methylene blue, ${ }^{44,45}$ malachite green, rhodamine B and brilliant green onto asoka leaf powder, ${ }^{43}$ walnut shell, ${ }^{10}$ bagasse pith activated carbon, ${ }^{29}$ jute stick powder. ${ }^{46}$

\section{Boyd model}

The Boyd model was used to analyze the kinetic data to predict the actual slow step involved in the adsorption process. The Boyd model reveals whether the adsorption is controlled by particle diffusion, where the adsorbate transport occurs within the pores, or by film diffusion, in which the transport occurs on the external surface. ${ }^{10}$

Boyd equation is presented as:

$\mathrm{B}_{\mathrm{t}}=-0.4977-\ln (1-\mathrm{F})$ 
where $\mathrm{F}$ is equivalent to $\mathrm{q}_{\mathrm{t}} / \mathrm{q}_{\mathrm{e}}$, which represents the fraction of adsorbate adsorbed at different time, and $\mathrm{B}_{\mathrm{t}}$ is the mathematical function of $\mathrm{F}$.

According to the Boyd model, the adsorption process is controlled by particle diffusion if the linear plot of $B_{t}$ vs $t$ passes through the origin. If the linear plot does not pass through the origin, then the adsorption process is controlled by film diffusion. The plots of $\mathrm{B}_{\mathrm{t}} \mathrm{vs} t$ for the adsorption of dyes MG, MB and RB onto RSS are shown in Figure

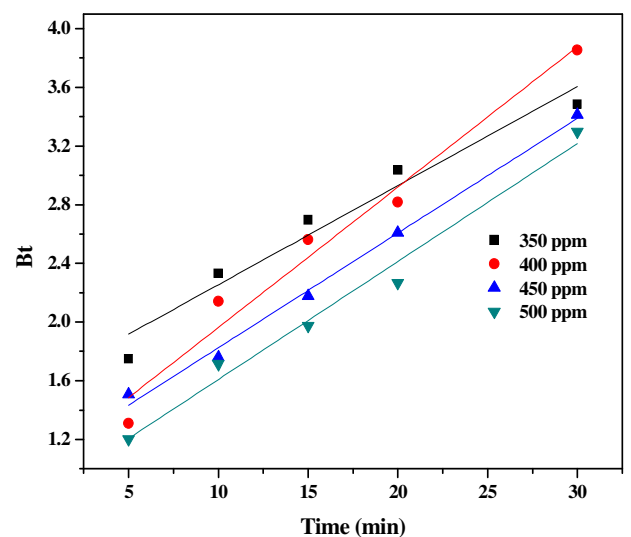

a)


b)

c)

Figure 14: Boyd plots for the adsorption of a) MG, b) MB, and c) RB onto RSS

The linear plot of $B_{t} v s t$ for all the dyes studied does not pass through the origin, suggesting that the adsorption process might be controlled by film diffusion. Similar results have been reported in the literature for the adsorption of malachite green on walnut shell, ${ }^{10}$ rattan saw dust $^{47}$ and wood apple shell. ${ }^{48}$

\section{Desorption studies}

The regeneration of the adsorbents is a very significant step in making the adsorption process more economical for industrial applications. The mechanism of adsorption and possible recovery of the adsorbate and of the adsorbent were investigated by conducting desorption studies.
Distilled water, hydrochloric acid (0.1M) and acetic acid $(0.1 \mathrm{M})$ were used for the desorption of the dyes MG, MB and RB. The desorption studies were carried out at $30 \pm 2{ }^{\circ} \mathrm{C}$. Table 6 shows the desorption efficiency of RSS with respect to the three dyes: MG, MB and RB. If the dye adsorbed can be desorbed by water, a weak interaction exists between the dye molecules and the adsorbent. If strong acids, such as $\mathrm{HCl}$, can desorb the dye, the interaction would be of the ion exchange type. The adsorption process might be chemisorption if the dye adsorbed can be desorbed by a weak acid, such as $\mathrm{CH}_{3} \mathrm{COOH} .{ }^{25,29,49}$ In the case of $\mathrm{MG}$, higher desorption takes place in $\mathrm{CH}_{3} \mathrm{COOH}$, suggesting 
the chemisorption of MG. The dyes MB and RB show higher desorption in $\mathrm{HCl}$, compared to distilled water and $\mathrm{CH}_{3} \mathrm{COOH}$, suggesting the ion exchange mechanism of adsorption of both dyes. Similar behavior has been observed for MB in silkworm exuviae, ${ }^{25}$ wheat straw materials, ${ }^{50}$ citric acid modified kenaf fibres. ${ }^{42}$

\section{Studies related to the removal of dyes from synthetic wastewater}

The wastewater from textile manufacturing or dye processing industries usually contains various types of suspended and dissolved compounds, apart from dyes. Metal cations, such as $\mathrm{Na}^{+}, \mathrm{K}^{+}$,
$\mathrm{Cu}^{2+}$, and $\mathrm{Ca}^{2+}$, are the most common metal ions present in wastewater. The presence of these metal ions leads to high ionic strength, which may significantly affect the efficiency of the adsorption process. ${ }^{51}$ To investigate the potential of the adsorbent for industrial wastewater, synthetic wastewater containing all the three dyes studied was prepared and its composition is presented in Table 7. The percent removal of the synthetic dye mixture increased with the increase in adsorbent dosage and the maximum color removal was observed at an adsorbent dose of 14 $\mathrm{g} / \mathrm{L}$.

Table 6

Desorption efficiency of the adsorbents

\begin{tabular}{lccc}
\hline Dyes & MG & MB & RB \\
\hline Dye concentration (mg/L) & 500 & 200 & 50 \\
Adsorbent dose (g) & 0.2 & 0.2 & 0.2 \\
Equilibrium time (min) & 60 & 60 & 80 \\
Removal efficiency (\%) & 92 & 98.7 & 87.6 \\
Desorption efficiency in $\mathrm{H}_{2} \mathrm{O}(\%)$ & 16.5 & 0.526 & 3.1 \\
Desorption efficiency in $\mathrm{HCl}(\%)$ & 20 & 31.15 & 27.4 \\
Desorption efficiency in $\mathrm{CH}_{3} \mathrm{COOH}(\%)$ & 40 & 26.23 & 10.3 \\
\hline
\end{tabular}

Table 7

Composition of synthetic wastewater containing the three dyes

\begin{tabular}{lc}
\hline Characteristics & Values \\
\hline $\mathrm{pH}$ & 11.0 \\
Conductivity (mS/cm) & 0.109 \\
Sodium (mg/L) & 1110 \\
Calcium $(\mathrm{mg} / \mathrm{L})$ & 700 \\
Potassium $(\mathrm{mg} / \mathrm{L})$ & 950 \\
Iron $(\mathrm{mg} / \mathrm{L})$ & 20 \\
Malachite green $(\mathrm{mg} / \mathrm{L})$ & 50 \\
Methylene blue $(\mathrm{mg} / \mathrm{L})$ & 50 \\
Rhodamine B (mg/L) & 10 \\
\hline
\end{tabular}

Figure 15 shows the effect of $\mathrm{pH}$ on the color removal of synthetically prepared dye wastewater and the single dye solutions. The percent color removal decreased with the increase in $\mathrm{pH}$ from 2 to 11 . This might be attributed to the fact that wastewater is associated with presence of various ions, such $\mathrm{Na}^{+}, \mathrm{Ca}^{2+}, \mathrm{K}^{+}$and $\mathrm{Fe}^{2+}$, which could compete with positively charged dye molecules for the same binding sites on the adsorbent surface in the wastewater. ${ }^{52}$ 


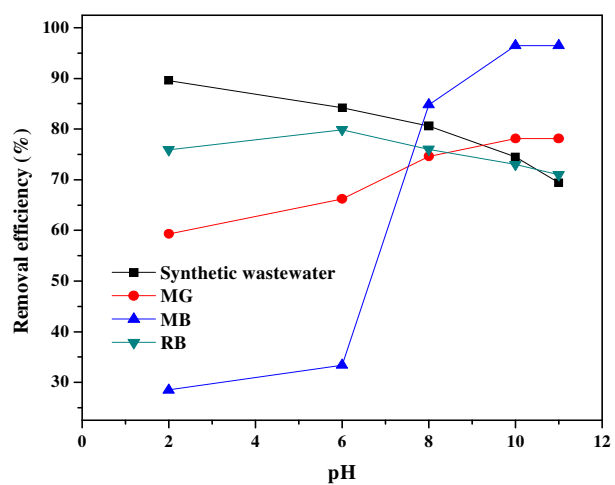

Figure 15: Effect of $\mathrm{pH}$ on the adsorption of synthetic wastewater and dyes MG, MB and RB by RSS

\section{CONCLUSION}

Simarouba glauca seed shell powder can be used as an efficient adsorbent for the removal of dyes Malachite green, Methylene blue and Rhodamine B from aqueous solutions. The isotherm data fitted well the Langmuir isotherm, with maximum adsorption capacity values of 200 , 76.92 and $33.33 \mathrm{mg} / \mathrm{g}$ for $\mathrm{MG}, \mathrm{MB}$ and $\mathrm{RB}$, respectively. The adsorption of the dyes followed second-order rate expression and the process of adsorption might be due to film diffusion. Desorption studies revealed the mechanism of dye adsorption. Malachite green followed the chemisorption mechanism, whereas Methylene blue and Rhodamine B followed the ion exchange mechanism.

\section{REFERENCES}

1 V. Gupta and Suhas, J. Environ. Manage., 90, 2313 (2009), https://doi.org/10.1016/j.jenvman.2008.11.017

2 V. I. Grover, "Water Global Common and Global Problems", Enfield, NH, Science Publishers, 2006, https://thesciencepublishers.com

3 W. Zhang, H. Li, X. Kan, L. Dong, H. Yan et al., Bioresour. Technol., 117, $40 \quad$ (2012), https://doi.org/10.1016/j.biortech.2012.04.064

4 J. Song, W. Zou, Y. Bian, F. Su and R. Han, Desalination, $\quad 265, \quad 119 \quad$ (2011), https://doi.org/10.1016/j.desal.2010.07.041

5 V. Garg, R. Kumar and R. Gupta, Dyes Pigments, 62, 1 (2004),

https://doi.org/10.1016/j.dyepig.2003.10.016

6 G. Mckay, J. Chem. Technol. Biotechnol., 32, 759 (1982), https://doi.org/10.1002/jctb.5030320712

S. M. D. O. Brito, H. M. C. Andrade, L. F. Soares and R. P. D. Azevedo, J. Hazard. Mater., 174, 84 (2010), https://doi.org/10.1016/j.jhazmat.2009.09.020

8 S. Jain and R. V. Jayaram, Desalination, 250, 921 (2010), https://doi.org/10.1016/j.desal.2009.04.005

9 J. Shah, M. R. Jan, A. Haq and Y. Khan, Front. Chem. Sci. Eng., 7, 428 (2013), https://doi.org/10.1007/s11705-013-1358-X
10 M. K. Dahri, M. R. R. Kooh and L. B. Lim, J. Environ. Chem. Eng., 2, 1434 (2014), https://doi.org/10.1016/j.jece.2014.07.008

11 C. K. Enenebeaku, N. J. Okorocha and A. O. Chris, Am. J. Chem. Mater. Sci., 2, 14 (2015), http://www.openscienceonline.com/journal/ajcms

12 S. Saroj, S. V. Singh and D. Mohan, Arab. J. Sci. Eng., 40, 1553 (2015), https://doi.org/10.1007/s13369015-1630-0

13 M. R. Malekbala, S. Hosseini, S. K. Yazdi, S. M. Soltani and M. R. Malekbala, Chem. Eng. Res. Des., 90, $704 \quad$ (2012), https://doi.org/10.1016/j.cherd.2011.09.010

14 C. Namasivayam and D. Kavitha, Dyes Pigm., 54, $47 \quad$ (2002), https://doi.org/10.1016/S01437208(02)00025-6

15 V. Garg, Dyes Pigm., 63, 243 (2004), https://doi.org/10.1016/j.dyepig.2004.03.005

16 H. Wang, X. Yuan, Z. Wu, L. Wang, X. Peng et al., Sep. Purif. Technol., 49, 2689 (2014), https://doi.org/10.1080/01496395.2014.940590

17 K. A. G. C. A. Gusmão, L. V. A. Gurgel, T. M. S. Melo and L. F. Gil, Dyes Pigm., 92, 967 (2012), https://doi.org/10.1016/j.dyepig.2011.09.005

18 P. Devan and N. Mahalakshmi, Fuel, 88, 1828 (2009), https://doi.org/10.1016/j.fuel.2009.04.025

19 C.-H. Weng, Y.-T. Lin and T.-W. Tzeng, J. Hazard. Mater., 170, $417 \quad$ (2009), https://doi.org/10.1016/j.jhazmat.2009.04.080

${ }^{20}$ K. A. Krishnan and A. Haridas, J. Hazard. Mater., 152, $527 \quad$ (2008), https://doi.org/10.1016/j.jhazmat.2007.07.015

21 E. K. Radwan, M. B. M. Ibrahim, A. S. Moursy and H. H. Abdel Ghafar, J. Environ. Sci. Technol., 12, 221 (2019), https://doi.org/10.3923/jest.2019.221.227

22 Y. Feng, H. Zhou, G. Liu, J. Qiao, J. Wang et al., Bioresour. Technol., 125, $138 \quad$ (2012), https://doi.org/10.1016/j.biortech.2012.08.128

${ }_{23}$ M. Doğan, H. Abak and M. Alkan, J. Hazard. Mater., $\quad 164, \quad 172 \quad$ (2009), https://doi.org/10.1016/j.jhazmat.2008.07.155

24 M. A. Ahmad and R. Alrozi, Chem. Eng. J., 171, 510 (2011), https://doi.org/10.1016/j.cej.2011.04.018 


\section{JEYAGOWRI BALAKRISHNAN and YAMUNA RANGAIYA THIAGARAJAN}

25 H. Chen, J. Zhao and G. Dai, J. Hazard. Mater., 186 1320

(2011), https://doi.org/10.1016/j.jhazmat.2010.12.006

26 M. Fernandez, G. Nunell, P. Bonelli and A. Cukierman, Bioresour. Technol., 101, 9500 (2010), https://doi.org/10.1016/j.biortech.2010.07.102

27 C. Namasivayam, M. D. Kumar, K. Selvi, R. A. Begum, T. Vanathi et al., Biomass Bioenerg., 21, 477 (2001), https://doi.org/10.1016/S0961-9534(01)000526

28 K. Kadirvelu, C. Karthika, N. Vennilamani and S. Pattabhi, Chemosphere, 60, 1009 (2005), https://doi.org/10.1016/j.chemosphere.2005.01.047

29 H. M. Gad and A. A. El-Sayed, J. Hazard. Mater.,

168 1070

(2009),

https://doi.org/10.1016/j.jhazmat.2009.02.155

30 S.-L. Hii, S.-Y. Yong and C.-L. Wong, J. Appl.

Phycol., 21, 625 (2009), https://doi.org/10.1007/s10811-009-9448-3

31 T. K. Sen, S. Afroze and H. M. Ang, Water Air Soil Pollut., 218, $499 \quad$ (2010), https://doi.org/10.1007/s11270-010-0663-y

32 E.-K. Guechi and O. Hamdaoui, Desalin. Water. Treat., $\quad 51, \quad 3371 \quad$ (2013), https://doi.org/10.1080/19443994.2012.749191

33 T. Santhi, S. Manonmani and T. Smitha, J. Hazard. Mater., $\quad 179, \quad 178 \quad$ (2010), https://doi.org/10.1016/j.jhazmat.2010.02.076

34 L. Wang, J. Zhang, R. Zhao, C. Li, Y. Li et al., Desalination, 254, 68 (2010), https://doi.org/10.1016/j.desal.2009.12.012

35 C. Namasivayam and R. Yamuna, Water Air Soil Pollut., $\quad 113, \quad 371$ (1999), https://doi.org/10.1023/A:1005080301379

36 R. Dod, G. Banerjee and S. Saini, Biotechnol. Bioprocess. Eng., 17, $862 \quad$ (2012), https://doi.org/10.1007/s12257-011-0614-5

37 D. Kavitha and C. Namasivayam, Bioresour. Technol., $\quad 98, \quad 14 \quad$ (2007), https://doi.org/10.1016/j.biortech.2005.12.008
38 H. E. Bakouri, J. Usero, J. Morillo and A. Ouassini, Bioresour. Technol., 100, $4147 \quad$ (2009), https://doi.org/10.1016/j.biortech.2009.04.003

39 Y.-S. Ho, Water Res., 40, 119 (2006), https://doi.org/10.1016/j.watres.2005.10.040

40 C. Xia, Y. Jing, Y. Jia, D. Yue, J. Ma et al., Desalination, $\quad 265, \quad 81 \quad$ (2011), https://doi.org/10.1016/j.desal.2010.07.035

${ }_{41}$ X. Han, J. Yuan and X. Ma, Desalin. Water. Treat., 52, $5563 \quad$ (2014), https://doi.org/10.1080/19443994.2013.813102

${ }^{42}$ M. S. Sajab, C. H. Chia, S. Zakaria, S. M. Jani, M. K. Ayob et al., Bioresour. Technol., 102, 7237 (2011), https://doi.org/10.1016/j.biortech.2011.05.011

43 N. Gupta, A. K. Kushwaha and M. Chattopadhyaya, J. Taiwan Inst. Chem. Eng., 43, 604 (2012), https://doi.org/10.1016/j.jtice.2012.01.008

44 M.-C. Shih, Desalin. Water. Treat., 37, 200 (2012), https://doi.org/10.1080/19443994.2012.661273

${ }_{45}$ V. Ponnusami, S. Vikram and S. Srivastava, J. Hazard. Mater., 152, $276 \quad$ (2008), https://doi.org/10.1016/j.jhazmat.2007.06.107

46 G. C. Panda, S. K. Das and A. K. Guha, J. Hazard. Mater., $\quad \mathbf{1 6 4}, \quad 374 \quad$ (2009), https://doi.org/10.1016/j.jhazmat.2008.08.015

47 B. Hameed and M. El-Khaiary, J. Hazard. Mater., 159, $574 \quad$ (2008), https://doi.org/10.1016/j.jhazmat.2008.02.054

${ }^{48}$ A. S. Sartape, A. M. Mandhare, V. V. Jadhav, P. D. Raut, M. A. Anuse et al., Arab. J. Chem., 10, S3329 (2017), https://doi.org/10.1016/j.arabjc.2013.12.019

49 C. Namasivayam, N. Muniasamy, K. Gayatri, M. Rani and K. Ranganathan, Bioresour. Technol., 57, 37 (1996), https://doi.org/10.1016/0960-8524(96)00044-2 50 W. Zhang, H. Yan, H. Li, Z. Jiang, L. Dong et al., Chem. Eng. J., 168, 1120 (2011), https://doi.org/10.1016/j.cej.2011.01.094

51 J.-X. Yu, B.-H. Li, X.-M. Sun, J. Yuan and R. Chi, J. Hazard. Mater., 168, $1147 \quad$ (2009), https://doi.org/10.1016/j.jhazmat.2009.02.144

52 A. Witek-Krowiak, Chem. Eng. J., 171, 976 (2011), https://doi.org/10.1016/j.cej.2011.04.048 